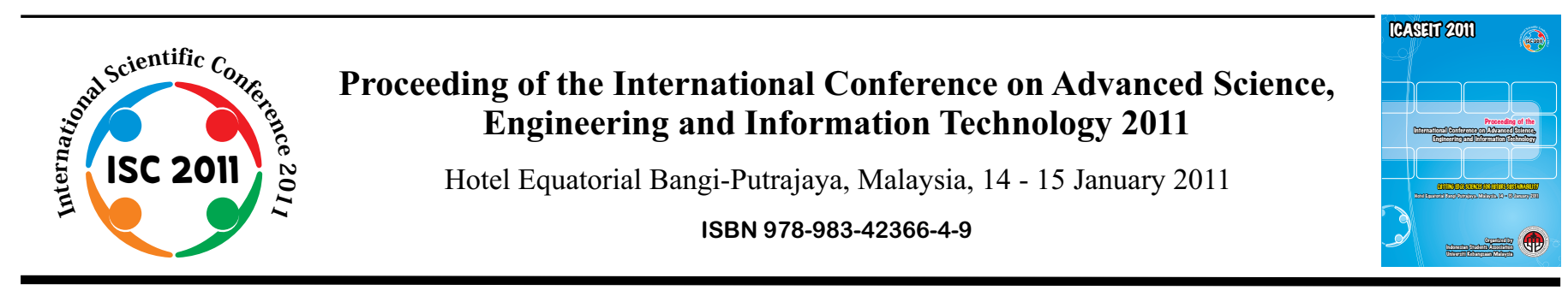

\title{
Multiple Intelligence Ensures Usability of Digital Storytelling for Preschool Children
}

\author{
Cut Nora Azizah ${ }^{1}$, Ariffin Abdul Mutalib², Nurulnadwan Aziz ${ }^{3}$, Rozana Mastura Abu Bakar ${ }^{1}$ \\ ${ }^{1}$ College of Arts and Sciences, University Utara Malaysia \\ 06010 Sintok, Kedah, Malaysia \\ ${ }^{2}$ International College, University of Science and Technology \\ Sana'a, Yemen \\ E-mail: ${ }^{1}$ cutnora79@yahoo.com; ${ }^{2}$ am.ariffin@uum.edu.my, ${ }^{3}$ nuruln746@tganu.uitm.edu.my,rmatura@yahoo.com
}

\begin{abstract}
This paper reports on an ongoing project that develops a learning material for preschool children. The concepts of courseware and digital storytelling (DST) are combined to deliver learning contents to students. The Multiple Intelligence is mapped into the developed learning material, which is called Preschool DST, in complementing the existing technologies such as books and courseware. The paper starts with some discussions on the background of the study, followed with the techniques used in the study. Then, lengthy discussions on the design and development of the Preschool DST follow, and finally the paper concludes by addressing the next step to perform. This study found that the Preschool DST is able to grab children's interest and engaging them during the learning process.
\end{abstract}

Keywords - Multiple intelligence, usable digital storytelling, learning material, preschool education, children

\section{INTRODUCTION}

Education is an essential aspect in human life. People seek the knowledge and increase their competencies through education. As the result of the rapid change and innovation in technology especially in the field of Information and Communication Technology (ICT), education system is forced to meet and adapt with the latest change and trend in the field. Multimedia technology as a branch of ICT is playing an important role in making the education system more interesting, efficient, and successful [1]. In fact, multimedia technology has become a popular tool in teaching and learning for every level of education. It has successfully complemented the traditional way of teaching and learning by putting more concerns on interactive aspects of education. In relation, interactive multimedia is basically employed to increase interactivity between student and teacher during the teaching-learning process using more than one media and at the same time, it might increase students' comprehensive understanding of the materials learned [2].

The term 'interactive multimedia' is a catch-all phrase to describe a wave of computer software that primarily deals with the provision of information. The 'multimedia' component is characterized by the presence of text, pictures, sound, animation and video [3]; some or all of which are organized into some coherent program making everything seamless [4]. Meanwhile, the 'interactive' component refers to the process of empowering the user to control the environment usually by computer [5][6][7]. In addition to its extensive use at higher learning institutions, as well as at primary and secondary learning education levels, interactive multimedia is also becoming a popular and effective tool for preschool education [8]. At the preschool level, where children love to learn things through storytelling, interactive digital storytelling (DST) can be an outstanding courseware for the preschool children to complement the printed books [9][10][11].

In Malaysia, according to MOSTI, the Malaysian government has recognized the role of ICT as a foundation condition in transforming Malaysia to be a K-based economy. The role of ICT was initially emphasized in the $6^{\text {th }}$ Malaysia Plan (RM6) mainly in the manufacturing sector. During RM7, the Malaysian government started to include eInitiatives including e-learning as a key catalyst in their National Information Technology Agenda (NITA). Further, in the RM8, smart school concepts were introduced and in the RM9, Malaysia started to engage with digital content development (e-Content) as one of the key components in 
the ICT Agenda. This initiative recognizes that educational digital content development was among areas of application under multimedia digital content strategies [12].

The implementations of content development initiatives are still being groomed. In relation, Ariffin and Massudi reported about a program that ensures students' employability in the areas of content development [13]. So, it is expected that the initiatives in content development will be put continuous emphasis in the $10^{\text {th }}$ Malaysia Plan (RM10). By having e-learning, smart school, and digital content agenda in hands, Malaysia has proven itself to be a fully information society that gives significant impacts to their national education quality including preschool education as aforementioned.

According to Karuović and Radosav, preschool children can be divided into two groups: children of 3-4 years old and children of 5-7 years old. For the 5-7 years old children, they might have some experiences of using computer, and they probably can read, count, and write [14]. These conditions perhaps allow the children to use the interactive DST more effectively in their daily learning. According to Pearman and Lefever-Davis, the use of interactive DST on CD-ROM and computer tends to be more interesting and engaging to readers which can enhance motivation to read [15]. It is more interesting because while they read the materials, at the same time, they can control all the activities in the story in accordance to their preferences. Also, visualization and audio interaction of the DST will surely increase children's ability in mastering the learning content. With these advantages, this study tries to examine the effectiveness of DST approach.

Additionally, this study relates the preschool children with individual differences addressed in the Multiple Intelligence (MI) theory [16]. In the theory, eight types of intelligences are outlined:

\section{- Verbal-Linguistic Intelligence}

Involves sensitivity to spoken and written language, the ability to learn languages and the capacity to use languages to accomplish certain goals.

- Mathematical-Logical Intelligence

Involves the capacity to analyze problems logically, carry out mathematical operations and investigate issues scientifically.

- Visual-Spatial Intelligence

Features the potential to recognize and manipulate patterns of wide space as well as patterns of more confined areas.

- Intrapersonal Intelligence

Involves the capacities to understand oneself, to have an effective working of oneself including one's own desire, fears and capacities and to use such information effectively in regulating one's own life.

- Bodily-Kinesthetic Intelligence

Entails the potential of using one's whole body or parts of the body to solve problems or fashion products.

\section{- Interpersonal}

Denotes a person's capacity to understand the intentions, motivations and desires of other people and consequently to work effectively with others.

- Naturalist Intelligence
Demonstrate expertise in the recognition and classification of the numerous species the flora and fauna of his or her environment.

- Musical-Rhythmic Intelligence

Entails skill in the performance, composition and appreciation of musical patterns.

\section{BACKGROUND}

A preliminary survey involving observations and interviews with teachers of a preschool has been carried out. In the survey, it was found that the school has been making use of multimedia courseware in their learning activities since previous years especially in Mathematics, Moral, Sciences, and English subjects. This study was also told that other preschools within the nearby locations are also making use of multimedia courseware. This means that multimedia courseware is used among children at preschools for teaching and learning purposes.

In definition, coursewares are developed for access through the web, or for use on CD. For instance, Baloian, Berges, Buschmann, Gaßner, Hardings, Hoppe, and Luther utilized courseware in their computer-integrated classroom as the content repositories [17]. In general, one of the advantages of courseware, in which hypertexts are utilized, is the ability for learners to read in different orders. Every page contains links to a number of different pages which can be read next. Basically in courseware, the 'browse and click' is the main interaction approach. Regan and Sheppard [18] classify the purposes of courseware as follows:

- to illustrate some design, development, and/or failure of devices/structures/systems; and to show relationships among design issues and devices.

- to contain exercises aimed at helping learners to better understand concepts through visual thinking.

- to serves as a guide, stepping learners through the various aspects (e.g. theory, physical setting) of performing physical experiments.

- as resources and references to complete assignment homework.

This study found that the courseware utilized in the preschools comply with the courseware defined in the previous paragraph. Users need to continuously click the mouse to operate the courseware. Although Norhayati reports that courseware is able to increase learners' rate of understanding through its ability to allow learners to clickand-browse [19]; view animations, simulations, and real videos; inquiry-and-feedback; self-determined order of navigation; other studies have found that courseware is not entertaining and not fun [20][21]. In particular, Ariffin and Norshuhada [21] and Karat et al. [22] found that users feel tired when they have to continuously click mouse in learning activities, so they prefer to click less and watch more.

Then, in complement of courseware, researchers design different forms of learning materials, such as video [23], Reality Learning Media (RLM) [24], and DST [25]. This study is attracted to these kinds of learning materials because they are more interactive than the text, audio, and picture based learning materials.

Among video, RLM, and DST, this study argues that DST is the most suitable for children. It has been a nature for 
children to have strong interests on storytelling [26][9]. However, DST has not been famous yet at preschool level. In the preliminary study, teachers were found not aware of the DST. The potentials of DST for use among children in teaching-learning activities have not been discovered. This needs urgent study, so that the recommendations over the DST could be made.

Considering the statements of problem posed, this study proposes the utilization of DST in preschool teachinglearning. Implementing DST in preschool is hoped to offer good learning experience to children. In accordance, this paper tries to achieve objectives as stated below.

The main objective of this study is to discover potentials of interactive DST among preschool children in their daily reading activities. This study proposes that this type of learning material is called Preschool DST. This paper presents part of the study, which aims at:

- determining the components of Preschool DST for preschool level

- developing a prototype of Preschool DST

\section{METHODS}

This study involves activities as illustratively depicted in Figure 1. The figure explains that there are two phases; Requirement analysis and Design and development. Each phase comprises further detailed activities. The detail explanation on each activity in the requirement analysis is provided in the following subsections. Meanwhile, the design and development of the Preschool DST are elaborated in Section 3.

\section{A. Interview}

The interviews involved teachers of a preschool as the subjects. It was aimed at gathering their experiences relating with children's reading activities. As teachers, they have the closest insight into children behavior and ability. Accordingly, their feedback will be good input for this study.

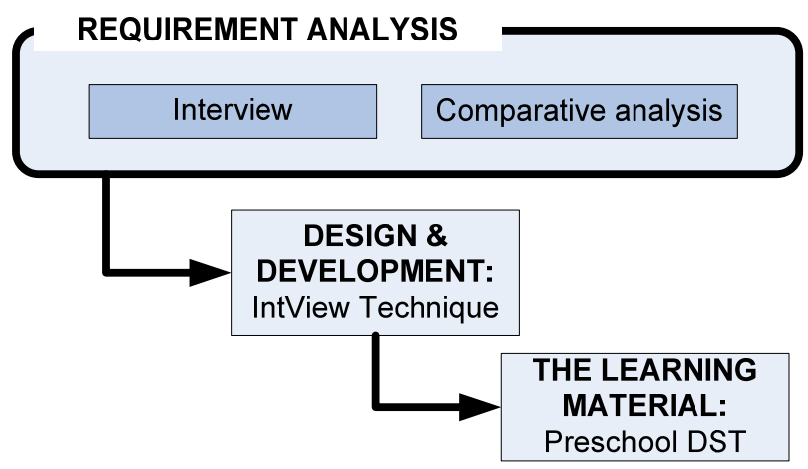

Fig. 1 Summary of works

In the interview, this study found that subjects emphasized on the content of learning material. They suggest that language is highly potential to be suggested with electronic learning material. Besides, mathematics and moral are also appropriate. Further, the subjects suggested that this study focuses on moral subject because the subjects believe that children will understand better if the moral subject is delivered through a DST material. The subjects also explained that they always start the activity by showing the title of the story first, and then they continue the learning activity with showing the pictures of each page and explain the content of the picture. Then, the real story is delivered to children with proper pronunciations and intonations.

In addition, the subjects also suggested about good criteria for the interface of a DST. The font must be big so that children can read easily. Also, a page should not more than four sentences [27]. Besides, background music or song is an important element in the DST, because preschool children are strongly engaged with musical elements. So, it is a good idea to integrate the musical elements to ensure that children learn with pleasure as suggested by some authors [27].

The interviews were then followed with a comparative analysis of the existing DST. This is important to confirm the findings of the interview regarding the components of the Preschool DST. Next section explains about the comparative analysis.

\section{B. Comparative Analysis}

This study has conducted a comparative analysis in supporting the findings of the interviews. Similar to the interview, the analysis is also aimed at gathering common components that should be included in the Preschool DST components related to multimedia and the interface.

In the comparative analysis, three DST for preschool children available in the market including on the internet were analyzed and compared. The titles of the three DST are 'Sang Musang dengan Kera', 'Tarzan', and 'Bananas for Lunch'. The first DST was adopted from the courseware of first year by Ministry of Education. The story is about a civet and a monkey in the jungle. This story is delivered in Malay language. Next is Tarzan which was developed for preschool and elementary school. The story is about a boy who lives in the jungle with a gorilla's family. The story is conveyed using Malay language. Finally, the third DST was adopted from the Public Library of Charlotte and Mecklenburg County for Preschool story part. The story is about one monkey which really likes to eat banana. It is presented in English.

This paper compares the DST in terms of their media components and the interface. The outcomes of the comparative study are discussed in the following.

\section{a. Multimedia Components}

Table 1 plots the similarity and difference of each DST in terms of multimedia component such as the animation, imagery, text, sound effect, background music, and voice over. These elements are suggested for inclusion in electronic learning material by many authors such as in [24] and [2]. Table 1 shows the multimedia components in DST available in the market or on the internet. From the table, animation, imagery, text, and voice over are components available in all DST. Animation is put in the preschool DST because children love to see moving and dynamic pictures. Image of each story represents the story text which is commonly short for preschool DST. Image can support the text. Text is provided to stimulate children for reading activity. Meanwhile, sound effect and background music are put to make the story alive while voiceover is to help the children in hearing the new vocabulary from the story. 
TABLE 1

Multimedia Components for samples of DST

\begin{tabular}{|l|c|c|c|}
\hline \multicolumn{1}{|c|}{$\begin{array}{c}\text { Multimedia } \\
\text { Component }\end{array}$} & DST 1 & DST 2 & DST 3 \\
\hline Animation & $\sqrt{ }$ & $\sqrt{ }$ & $\sqrt{ }$ \\
\hline Imagery & $\sqrt{ }$ & $\sqrt{ }$ & $\sqrt{ }$ \\
\hline Text & $\sqrt{ }$ & $\sqrt{ }$ & $\sqrt{ }$ \\
\hline Sound Effect & - & $\sqrt{ }$ & - \\
\hline Background Music & - & $\sqrt{ }$ \\
\hline Voice Over & $\sqrt{ }$ \\
\hline
\end{tabular}

For the DST 1, Table 1 shows that it has the animation component even thought it just appear in the beginning of the story, not in all story duration. This story just comes out with the same picture for every page of the story. The text combines with the voiceover as storyteller. The voiceover is audible without the background music and sound effect.

Next, the DST 2 also has the animation in the opening of DST. Picture is changed for every page of the story. The text is also combined with the voiceover as the storyteller. This DST displays different pictures which support each text for every page. The voiceover is audible with sound effect and background music that make the story alive.

The DST 3 entitled 'Bananas for Lunch' is the last DST compared. The animation is shown for all duration of the story. The image just appears once with the same picture but with the animated the banana picture. The text is just using one sentence for each picture with the voiceover as the storyteller. It also uses the sound effect similar to one in the second DST but without the background music.

\section{b. Interface Components}

Table 2 plots the similarity and difference of each DST in terms of the interface. This study tends to emphasize on the interface because preschool children may need special attention to ensure their psychomotor are well supported. So, background color, font size, icon color, icon size, and interactivity are determined. In Table 2 the interface component i.e. background color, font size, icon color, icon size, and interactivity are compared. The background color is important to catch the attention of the preschool children when they interact with the learning materials for the first time. Font size is also important to allow users read the story easily. This will differ for different user groups. The size and color of the icon are to show the story direction clearly. Interactivity is provided to give them opportunity to explore the learning content on their preferred way.

Table 2 shows interface component for DST 1 such as for the background of the story that uses the soft blue color. The icon is big with colorful performance. This story just has the back icon to the previous pages without has the next page icon. The next page is automatically changed by the system. So, for the interactivity, the users just make the preference for back to the previous page. In addition, it has a long story duration and the font is small.

The second DST is available with the navigation icons to make the user choose their preference. These icons are shown with the big size and colorful icons. From the interactivity part, some icons can be clicked by the user in order to explore their preference. Yet, the color selection for the background which used the dark color (black) is not too suitable for the preschool student. The font size is big but the story is too long for the preschool.

TABLE 2

Interface Components for Samples of DST

\begin{tabular}{|l|c|c|c|}
\hline \multicolumn{1}{|c|}{$\begin{array}{c}\text { Interface } \\
\text { Component }\end{array}$} & DST 1 & DST 2 & DST 3 \\
\hline Background Color & Soft color & Dark color & Soft Color \\
\hline Font Size & Small & Big & Big \\
\hline Icon Color & Colorful & Colorful & Colorful \\
\hline Icon Size & Big & Big & Big \\
\hline Interactivity & Yes & Yes & Yes \\
\hline
\end{tabular}

As in the first DST, DST 3 also uses the soft blue color as its background. The pictures also use bright colors to show cheerful situation. The size of the text is big and it is very suitable for the preschool student. The icon used is big with sign and text to navigate the user. But the navigational icon just available for the next page, the user cannot click to go to the previous page. In addition to the interactivity involved in clicking the icons, it also can be seen when the user clicks the picture, the picture will make sound or movement. Besides that, this story content involves the math subject which is presented by number of bananas.

From all of the three DST compared, they show that the common components from the multimedia and interface component are animation, image, text, sound effect and voiceover. While the interface, the use of color should be cheerful with the soft color or bright color. The big icon with clear instruction should be utilized. The text with big size font is more suitable for preschool student. From these common components, this study developed the prototype of interactive DST with include animation, image, text, sound effect, voice over as storyteller and background music to make the story seem alive. Appropriate icon size is designed to give a comfort to the preschool children. In addition, because the preschool students like to see the animation, in the text is also added some picture with animation. The picture is managed to suit with the word in the story text.

Moreover, moral value of the story is included after the story reading. In the menu page, users can find retelling story icon to give more comprehension of the story to the students. Another menu is also added such as music because from the explanation of the teacher, it revealed that the preschool students love music or song.

\section{IV.DESIGN AND DEVELOPMENT}

In this study, the development of Preschool DST prototype adapted the IntView courseware development methodology. Grützner, Pfahl, and Ruhe [28] found that the IntView decreases the efforts necessary to develop large courseware extensively. In addition, other authors found that the method assures courseware quality [29][30]. More importantly, the IntView is adapted into this study because the first IntView framework suggests steps for developing online courseware, while this study will develop the Preschool DST on CD. In fact, some authors have also utilized the IntView in developing small scaled normal courseware, DST, and courseware for the hearing-impaired students [9][31][32]. Hence, there are some steps eliminated in this study during prototype development. There are two 
phases in IntView; pre-development phase and development phase as illustrated in Figure 4 (see Appendix).

In this study, the design and development activities of the Preschool DST are divided into two stages; pre-development and development stage. Brief outcome of each step in Figure 4 are outlined in Table 3 (see Appendix).

This study does not publicize the Preschool DST, rather it is used specifically for study. From the storyboard, a working prototype has been developed. This study incorporates intelligence elements in the MI as discussed earlier into the Preschool DST. Accordingly, Figure 5 (see Appendix) provides some snapshots of the Preschool DST with the intelligence elements. The Preschool DST has been presented to the preschool Children. Summaries of the presentation are concluded in the next section.

\section{CONCLUSION}

When the Preschool DST was presented to the target users, which are the preschool children, they were found to be very excited with the learning material. In that initial trial for user feedback, this study found that all students regardless of their academic achievement responded positively, and looking forward to use the Preschool DST in their learning activity. This shows that the Preschool DST is initially found usable by the children.

This study interprets that the concept of DST could be utilized in delivering learning contents to preschool learning materials. For the next step, this study tends to elaborate indepth on the components of the Preschool DST that captures the children's attention most. Discussion in this paper is based on an initial work for collecting users' feedback. However, a systematic procedure has not been carried out. Hence, this study plans to carry out a systematic data collection on users' feedback, to determine how the Preschool affects the preschool children's' behavior in learning activities with the Preschool DST. In addition, this study will also look into the potentials of the Preschool DST for implementation in preschools with the children.

\section{REFERENCES}

[1] Hardaway, D., \& Will, R. P. (1997). Digital multimedia offers key to educational reform. Communications of the ACM, 40(4), 90-96

[2] Zurina Muda. (2006). Storytelling in Multimedia Courseware: an introduction to science for preschool education. Information and Communication Technology ICCTA 2006, 2, p. 2991-2993.

[3] Chapman, N. \& Chapman, J. (2002). Digital Media Tools. John Wiley \& Sons, Ltd. England

[4] Faridah Hanim \& Halimah, B.Z. (2008). Development of interactive multimedia courseware using problem based learning in mathematics for Form 4. In Proceedings of International Symposium on Information Technology. 2. Kuala Lumpur: IEEE

[5] Phillips, R. (1997). The Developers Handbook to Interactive Multimedia. London: Kogan Page

[6] Jones, V. \& Jo, J. H. (1998). Interactive Multimedia based on Learning Theories to Enhance Tertiary Education, Conference Proceedings ICCIMA'98, Australia

[7] Chorianopoulos, K. \& Lekakos, G. (2007). Learn and play with interactive TV. ACM Computers in Entertainment. 5(2)

[8] Blas, N.D., et al. (2009). Digital Storytelling as a Whole-Class Learning Activity: lessons from a three years project. In Proceedings of ICIDS 2009, LNCS 5915, Springer, p.14-25
[9] Ariffin A.M. (2010). Digital Storytelling: An Easy-to-create Usable Information Conveyor. J. of Info. Tech. Review 1(1). 34-41

[10] Digital Storytelling Association. (2002). Digital Storytelling. [Online] http://www.dsaweb.org/ [6 March 2010]

[11] Meadows, D. (2003). Digital Storytelling: Research-based practice in new media. Visual Communication. 2(2). 189-193

[12] MOSTI. (2010). Strategic ICT Roadmap for Malaysia. [Online] http://www.mosti.gov.my [22 July 2010]

[13] Ariffin A.M. \& Massudi M. (2010). Student Marketability: Enhancing Software Skills. Issues in Informing Science and Information Technology. 7. 413-422

[14] Karuović, D. \& Radosav, D. (2009). Educational Software for Preschool Children. Intelligence and Informatics 2009, p. 291-295

[15] Pearman, C. \& Lefever-Davis, S. (2006). Supporting the Essential elements with CD-ROM Digital Storytelling. Reading Horizon Journal, 46 (4), pp. 301-313

[16] Gardner, H. (1993). Multiple Intelligences: The Theory in Practice, NY. Basic book

[17] Baloian, N. et al. (2002). Document Management in a Computer Integrated Classroom. In Proceedings of CRIWG 2002, $8^{\text {th }}$ International Workshop on Groupware, LCNS, Springer.

[18] Regan, M. \& Sheppard, S. (1996). Interactive multimedia courseware and the hands- on experience: an assessment study. Journal of EngineeringEeducation. April 1996. 123-131

[19] Norhayati A.M. (1999). Perisian Pengarangan. Petaling Jaya: Prentice Hall

[20] Karat, C. et al. (2001). Less clicking, more watching: Results of the iterative design and evaluation of entertaining web experiences. In Proceedings of Interact'2001, Tokyo, Japan

[21] Ariffin A.M. \& Norshuhada, S. (2008). Usable but not entertaining eLearning materials. In Proceedings of World Conference on eLearning in Corporate, Government, Healthcare, and Higher Education (e-Learn), USA. AACE

[22] Karat, C. et al. (2001). Less clicking, more watching: Results of the iterative design and evaluation of entertaining web experiences. In Proceedings of Interact'2001, Tokyo, Japan

[23] Cennamo, K. S. (1993). Learning from video: factors influencing learners' preconceptions and invested mental effort. Educational Technology Research and Development, 41(3), 33-45

[24] Ariffin A.M. \& Norshuhada, S. (2009). Conceptual design model of Reality Learning Media (RLM). In Proceedings of IADIS International Conference e-Society 2009, Barcelona, Spain. IADIS

[25] Churchill, N., et al. (2008). Digital storytelling and digital literacy learning. In Proceedings of International Conference on Information Communication Technologies in Education (ICICTE) 2008. 418-430

[26] Widjajanto, W.A. ET AL. (2008). "Wayang authoring": A web-based authoring tool for visual storytelling for children. In Proceedings of The $6^{\text {th }}$ International Conference on Advances in Mobile Computing \& Multimedia (MoMM2008). 464-467. Austria: ACM

[27] Rohizani Yaakub \& Hazri Jamil. (20090. Panduan Bercerita untuk Prasekolah. Kuala Lumpur: PTS Professional Publishing

[28] Grützner, I. , Pfahl, D. \& Ruhe, G. (2002). Sistematic Courseware Development Using an Integrated Engineering Style Method. In Proceedings of the World Congress Networked Learning in a Global Environment: challenges and solutions for virtual education. Technical University of Berlin, Germany

[29] Grützner, I., Angkasaputra, N., \& Pfahl, D. (2002). A Systematic Approach to Produce Small Courseware Modules for Combined Learning and Knowledge Management Environment. In Proceedings of $14^{\text {th }}$ International Conference on Software Engineering and Knowledge Engineering (SEKE), Italy, pp. 533-539

[30] Grützner, I., Weibelzhal, S., \& Waterson, P. (2004). Improving Courseware Quality through Life-cycle Encompassing Quality Assurance. In Proceedings of the 2004 ACM Symposium on Applied Computing, Cyprus, pp.946-951

[31] Ariffin A.M. (2009). Conceptual Design of Reality Leraning Media (RLM) Model based on Fun and Entertaining Constructs. Unpublished PhD Thesis, Universiti Utara Malaysia.

[32] Ariffin A.M. \& Faizah M. (2010). Guideline of Assistive Courseware for Hearing Impact Students. In Proceedings Knowledge Management International Conference 2010, Thompson-ISI. 


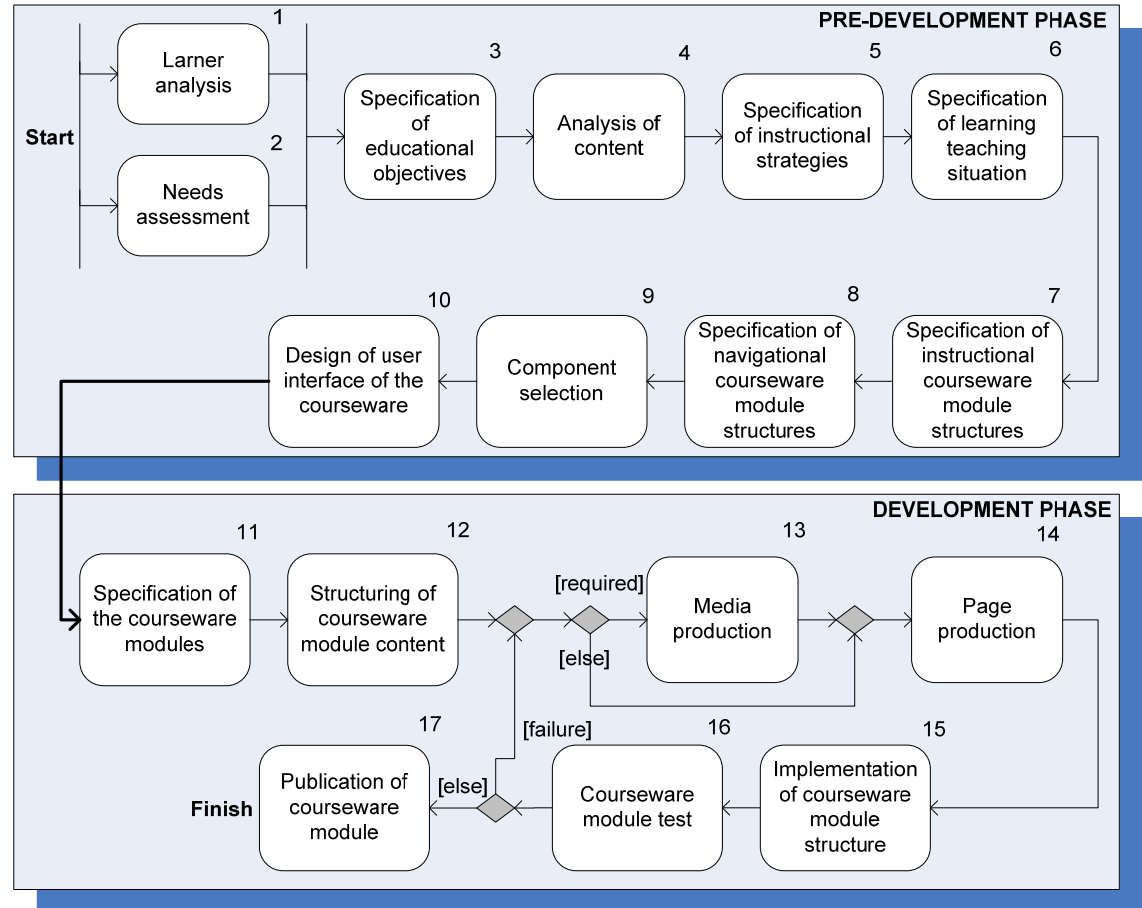

Fig.4 Preschool DST development method

Table 3: Activity and output of steps in adapted IntView

\begin{tabular}{|c|c|c|c|}
\hline Stage & Activity / Output & Stage & Activity / Output \\
\hline 1 & $\begin{array}{l}\text { Preschool students' learning profile including their special needs for } \\
\text { on-screen elements. }\end{array}$ & 10 & $\begin{array}{l}\text { Some templates are drafted, and the most desired is obtained } \\
\text { here. }\end{array}$ \\
\hline 2 & $\begin{array}{l}\text { - All contents for the Preschool DST } \\
\text { - The interface must be suiting the target audience as specified in } \\
\text { the learner analysis. } \\
\text { - Skills in composing Preschool DST (intermediate fidelity } \\
\text { prototype). }\end{array}$ & 11 & $\begin{array}{l}\text { The development phase begins here. } \\
\text { The contents of the Preschool DST are determined as the } \\
\text { modules. All detailed information for activities in pre- } \\
\text { development phase will be used as the pre-requisites in this } \\
\text { stage. }\end{array}$ \\
\hline 3 & As stated by the teachers. & 12 & $\begin{array}{l}\text { Each module is presented in an exclusive page. When the } \\
\text { information to deliver is not enough, then sub-pages is used. }\end{array}$ \\
\hline 4 & Must meet the requirements in the course objectives. & 13 & Text, picture, graphic, and other media elements are composed. \\
\hline 5 & $\begin{array}{l}\text { The learners may need special instructional strategies. This will be } \\
\text { based on the components. }\end{array}$ & 14 & $\begin{array}{l}\text { The pages are developed. All details in the activities previously } \\
\text { are considered. }\end{array}$ \\
\hline 6 & $\begin{array}{l}\text { Learners use the Preschool DST with their teachers in their } \\
\text { classroom. }\end{array}$ & 15 & $\begin{array}{l}\text { The pages are arranged as intended, as designed in the } \\
\text { storyboard. All navigational elements are made working. }\end{array}$ \\
\hline 7 & $\begin{array}{l}\text { - Interactivity between user and Preschool DST is required. } \\
\text { - Tool-tip texts are used when necessary. }\end{array}$ & 16 & $\begin{array}{l}\text { This study adapts testing procedure to ensure the Preschool DST } \\
\text { quality from the work of Grưtzner et al. (2004). }\end{array}$ \\
\hline 8 & $\begin{array}{l}\text { Hybrid navigation style among modules. Within modules are linear } \\
\text { navigational to support next-and-next task sequences. The } \\
\text { storyboard is outlined at this stage and is provided in Figure } 5 .\end{array}$ & 17 & The Preschool DST is not publicized, used only for this study. \\
\hline 9 & $\begin{array}{l}\text { There is no special component. The details of the instructional and } \\
\text { navigational structures are used to determine the components } \\
\text { required. The development activities could begin at this stage. }\end{array}$ & & \\
\hline
\end{tabular}



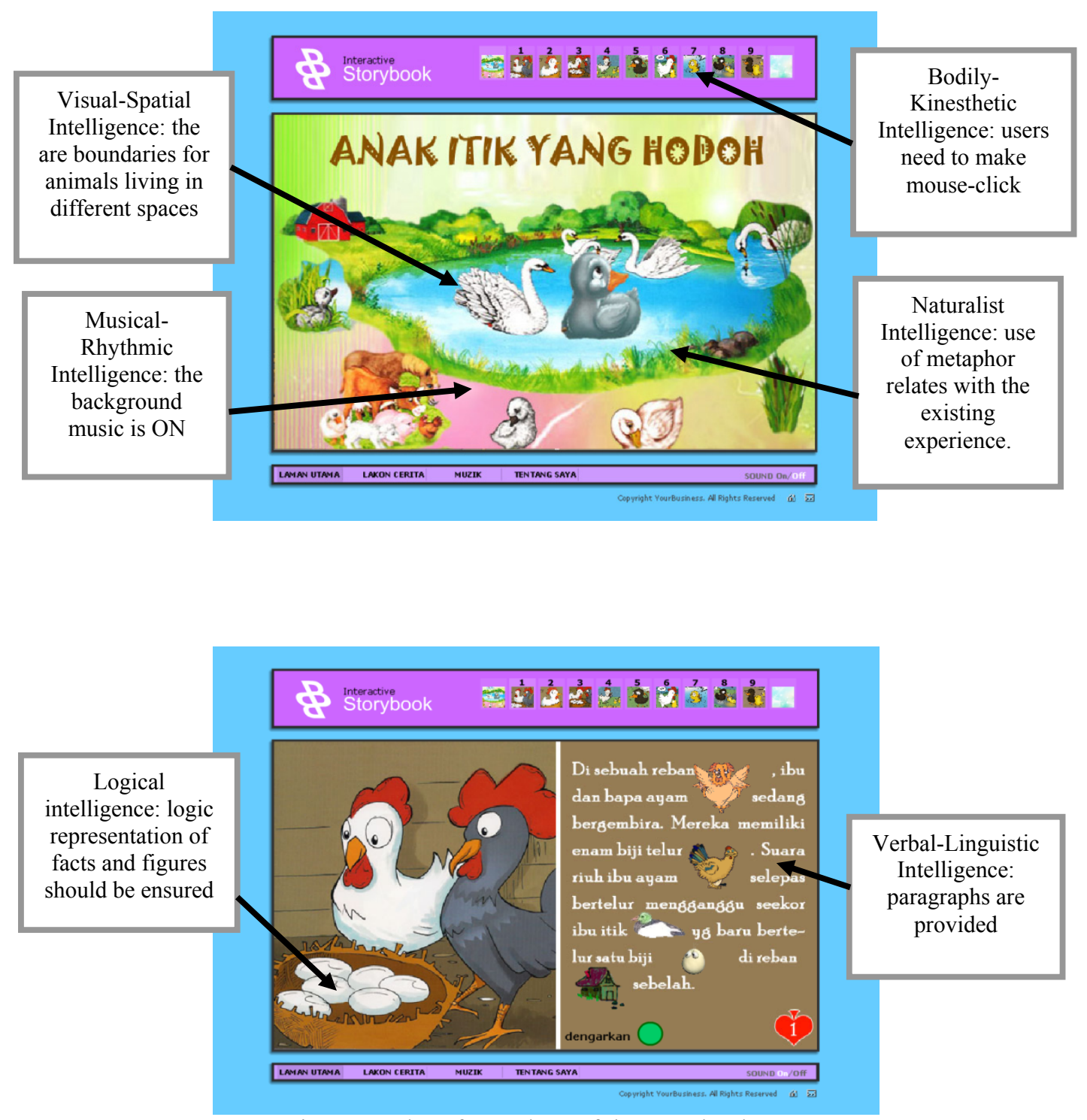

Fig.5 Samples of snapshots of the Preschool DST 